\title{
XIV \\ EDUCAÇÃO, REALIDADE AMAZÔNICA E FORMAÇÃO DO \\ PROFESSOR: O PARTICULAR E O UNIVERSAL
}

Leane Lima Oliveira ${ }^{1}$

\section{Introdução}

Os professores que atuam na educação da região Amazônia devem ter clara concepção de educação e conhecimento da região, frente ao desafio de uma educação crítica, transformadora e emancipadora da gente da cidade, do campo, ribeirinhos, indígenas, quilombolas, seringueiros, nativos e imigrantes, imersos como conflitos ambientais, disputas por territórios, desmatamento, desrespeito à diversidade, desvalorização da cultura local. Tais questões na maioria das vezes são excluídas ou minimizadas no currículo escolar e no desenvolvimento do ensino e aprendizagem. Tendo isso em vista, este artigo tem como questão fundamental pensar, na realidade Amazônica, a formação do professor, em torno da tensão entre o particular e o universal. Para tanto, organiza-se em três momentos.

No primeiro, considera a educação como tal - sua finalidade, dinâmica e funcionamento - desde duas concepções bastante distinta, de fato, em oposição. A primeira, ingênua, traz postura que simula neutralidade, está ligada à concepção tradicional da educação e de ensino-aprendizagem. A segunda, própria de uma educação crítica, surge como uma nova pedagogia, cujo ponto de partida e de chegada são a prática social, em um movimento dialético no qual educador rompe com a neutralidade

*DOI - 10.29388/978-65-86678-45-1-0-f.327-342

${ }^{1}$ Mestranda em Educação da Universidade Federal do Oeste do Pará/UFOPA, Linha de Pesquisa: Linha 2. Conhecimento e formação na educação escolar, sob a orientação do Prof. Dr. Luiz Percival Leme Britto. 
e assume postura aberta diante do conhecimento, entendido como produção histórica.

No segundo momento, reflete sobre a educação na Amazônia, enfocando a tensão particular e o universal e pensando uma educação na Amazônia que considere sua realidade, singularidades e especificidades.

No terceiro momento, tece considerações sobre como vem ocorrendo com a formação do professor, a partir da aprovação da Lei de Diretrizes e Bases da Educação Nacional - LDB, no 9394/1996, especialmente no que tange às disputas entre público e privado, observando que o recuo da teoria nos cursos de formação inicial tem implicações na prática pedagógica.

\section{O professor e sua concepção de educação}

Podemos dividir as concepções de educação em duas grandes vertentes: uma em que se encaixam os que aderem e professam uma visão ingênua do mundo e sociedade - e por consequência, de educação; e outra, de postura crítica, que rompe com a neutralidade, focando o trabalho na formação de indivíduos pensantes, autores e produtores de sua realidade, com postura transformadora e emancipadora.

$\mathrm{Na}$ primeira vertente - concepção tradicional da educação -, ancorada em teorias e posturas próprias do ensino tradicional, ora o professor é o centro, ora é o aluno, ora é o conteúdo - não há relação horizon tal entre os sujeitos, a relação é sempre vertical e a prática educativa segue a lógica das teorias mecanicistas de ensino e aprendizagem, conforme os pressupostos da metafísica e da linha positivista.

A segunda vertente - educação crítica e emancipadora de educação - tem como característica principal o rompimento com a neutralidade e com o pensamento hegemônico, sendo a prática social o ponto de partida e o ponto de chegada, de modo que a relação teoria e prática ocorre num movimento dialético, num ir e vir constantes, continuamente em novas sínteses, gerando um conhecimento mais elaborado.

Quanto as bases teóricas da pedagogia histórico-crítica, é obvio que a contribuição de Marx é fundamental. Quando pensamos 
fundamentos teóricos, observa-se que, de um lado, está a questão da dialética, essa relação do movimento e das transformações; e, de outro, que não se trata de uma dialética idealista, uma dialética entre os conceitos, mas uma dialética do movimento real. Portanto, trata-se de uma dialética histórica expressa do materialismo histórico, que é justamente a opção que procura compreender e explicar o todo desse processo, abrangendo desde a forma como são produzidas as relações sociais e suas condições de existência até a inserção da educação nesse processo. (SAVIANI, 2013, p. 119120).

A pedagogia histórico-critica, que tem seus pressupostos epistemológicos no pensamento marxista, faz reflexão sobre a sociedade atual, capitalista, na qual os donos dos meios de produção - o capital - detêm a hegemonia econômica, política e cultural, impondo modelos de vida e de educação em conformidade com seus interesses. Os trabalhadores, a classe subalterna, são sempre explorados.

Portanto, Libâneo relata que:

Ao conceber a educação como produto do desenvolvimento social e determinada pela forma de relações sociais de uma dada sociedade, põe-se como forma de relações sociais de uma dada sociedade, põe-se como crítica radical em relação a educação individualista. O vínculo da prática educativa como a prática social global faz vir á tona o fato de ela subordiná-se a interesses engendrados na dinâmica das relações entre grupos e classes sociais. Nessas condições, a educação tende não só a ser representativa dos interesses dominantes (consolidados pela ação do Estado), como também a ser transmissora da ideologia que responde a esses interesses. (2010, p. 79).

O sistema educacional burguês se orienta pela lógica dos interesses do capital, objetivado para qualificação da mão-de-obra e modos de pensar único e universal, caracterizado pela divisão do saber e pela sociedade dividida em classes sociais e por sua dependência aos processos de produção capitalista. 
Mas a educação para a garantia dos interesses do grupo do capital, mas não está imune a rupturas. Nesse sentido, é importante destacar que os objetivos da educação são tensos, servindo ora aos interesses da ideologia dominante, ora aos interesses das classes trabalhadoras. Como assinala Gramsci (1978), a educação pode produzir a contra-hegemonia, tendo intelectuais transformadores na linha de frente, como organizadores da cultura, criando possibilidades de construção de um ensino justo, democrático, que considere a diversidade e a pluralidade cultural em conexão e relação com os conhecimentos socialmente construídos. É somente com a aquisição dos conhecimentos sofisticados produzidos pela humanidade que conseguiremos superar as desigualdades sociais.

Nessa direção, Libâneo convida-nos a tomar posição rumo ao rompimento com a concepção de educação enquanto processo individualista, a-histórico e sem conexão com a reflexão da realidade, tendo por base a educação como prática educativa e humana, que ocorre no âmbito histórico e social. Para Saviani (2019), o papel do professor vai além da transferência do objeto de conhecimento, levando o aluno a pensar e a ser o sujeito da aprendizagem, crítico e refletindo sua realidade. Nesse processo, a educação escolar tem a função de instrumentalizar os alunos a superar as condições de desigualdades sociais, através do conhecimento.

\section{A educação na Amazônia: o particular e o universal}

A educação na Amazônia é marcada pela diversidade social, cultural, ambiental. Dentre os fatores relevantes, está a bagagem que os alunos trazem de suas vivências quando chegam à escola, pois vivem em diferentes espaços e territórios: cidade (e sua periferia), campo, ribeiras, quilombos, aldeias; isso implica saberes vários e problemáticas complexas que, na maioria das vezes, são desconsiderados no processo de ensino e aprendizagem escolar, com centralidade dada a um "currículo oficial" que desconsidera o que é próprio da Amazônia.

O público da educação escolar traz consigo saberes relativos à pesca, a floresta, ao cultivo da mandioca, arroz e outros grãos; traz, além 
disso, suas histórias, imaginários e representações presentes em suas práticas sociais que não podem ser desconsiderados. Tais saberes provém de sua cultura e da relação de trabalho com a terra, com a mata e com as águas, além das vivências comunitárias, e se expressam em dimensões educacionais, religiosas, medicinais, culturais e históricas.

A diversidade como traço marcante na formação histórico-social brasileira é algo indiscutível. Antropólogos, historiadores e diversos outros cientistas sociais já se lançaram a tarefa de identificar, definir e compreender a cultura brasileira em seus múltiplos aspectos. Independentemente de suas concepções ideológicas, concordam que existe uma acentuada e rica diversidade cultural, e não apenas uma diversidade na nossa composição étnica. Todavia, nem todos atribuem a esta diversidade a mesma importância e a consideram em sua riqueza, na medida em que ainda há quem assuma posição nitidamente enaltecedora de uma determinada cultura em detrimento de outra (s).(COLARES e COLARES, 2011,p. 11).

As políticas públicas educacionais realizadas pelo ministério da educação são as mesmas para todas as regiões do Brasil - o que não é necessariamente ruim; mas falta contextualização e formação de professores que dê conta de trabalhar a relação entre esses conhecimentos com os saberes específicos da região, em particular com os conhecimentos socialmente construídos da realidade Amazônica, que são tão importantes quanto para a formação dos sujeitos que vivem na região.

O sistema educacional e suas instituições escolares são produtos sociais historicamente construídos, são também modificáveis. Tanto podem contribuir para a reprodução das formas de conduta, das relações e dos conhecimentos que funcionam como requisitos para a manutenção de um modelo econômico, político, cultural e religioso fundamentado na desigualdade e reforçador das diferenças, quando podem promover a resistência a este modelo e propor a sua superação. Se a opção desejada estiver na perspectiva transformadora, é imprescindível o conhecimento da diversidade, 
como pressuposto de respeito e valorização (COLARES e COLARES, 2011, p. 3).

A Amazônia está submersa a disputas de interesses influenciados pelos interesses capitalistas. Dentre os fatores relevantes, destacam-se as disputas pela posse de terras, a destruição do ambiente pelo desmatamento e queimadas, a construção de hidrelétricas, a abertura de rodovias e estradas, a invasão de terras indígenas, a extração de minérios, o agronegócio, entre outras formas de exploração dos recursos naturais da Amazônia, que geram lucro para o capital nacional e internacional. Frente a essa realidade, desconsideram-se os interesses das populações locais e desrespeita-se a diversidade ambiental, social e cultural da região. Percebemos isso nas políticas educacionais que são pensadas, elaboradas e implementadas de maneira vertical pelos governantes, que desconsideram toda heterogeneidade e especificidades culturais, sociais e ambientais existentes nessa região.

É indiscutível a necessidade de elaboração de políticas públicas de proteção ambiental e cultural e social, com políticas que considerem os interesses dos povos dessa região. A Constituição Federal do Brasil de 1988, art. 210 estabelece que "serão fixados conteúdos mínimos para o ensino fundamental, de maneira a assegurar a formação básica comum e respeito aos valores culturais e artísticos, nacionais e regionais". Nesse sentido, existe preocupação em garantir o trabalho com a diversidade cultural, respeitando tanto a diversidade nacional como regional. Também a Lei de Diretrizes e Bases da Educação Nacional, de 1996, atenta para isso e determina que se deve se incluir no currículo da Educação Básica uma parte de conteúdos que prevê a diversidade cultural e regional no contexto do território brasileiro.

Contudo, apesar de contemplado nos textos legais da Constituição Federal de 1988 e Lei de Diretrizes e Bases da Educação Nacional de 1996, o anseio do trabalho com a diversidade aparece de maneira tímida e superficial, não obstante as lutas de movimentos dos povos indígenas, movimento negro e movimento feminista, entre outros, que propugnaram, nas conferências municipais, estaduais e nacional de educação, realizadas entre 2010 a 2014, com objetivo, discutir com a sociedade, ações, 
metas e estratégias do Plano Nacional de Educação - PNE, para que tais temas ganhassem evidência e relevância no currículo escolar.

Entretanto, nem todas as pautas relativas à diversidade foram contempladas no documento final do PNE, sob a Lei no 13.005 de 2014. A leitura atenta e crítica do documento revela continuidades de desigualdades históricas no que se refere ao trabalho com a diversidade no âmbito da educação brasileira e amazônica. Há muita reflexão a ser feita para instituir uma educação que considere a realidade Amazônica em sua singularidade e a necessária articulação com os conhecimentos historicamente acumulados pela humanidade.

De acordo com Arroyo e Gomes (2017), ao introduzir o direito à diversidade como uma de suas diretrizes, o PNE (2014 - 2024) o reconhece como um dos direitos básicos da sociedade brasileira, mas nem todas as reivindicações dos movimentos sociais e as pautas defendidas nas conferências municipais, estaduais e nacional de educação, foram contempladas nas metas e estratégias do referido plano. Muitas delas, especialmente sobre educação e diversidade, permanecem transversalisadas de maneira conservadora ou foram invisibilizadas.

A Base Nacional Comum Curricular (BNCC), aprovada em 2017, estabelece as competências e habilidades que todo estudante deve ter adquirido ao final da formação escolar básica. Essas competências pressupõem capacidade de resolver problemas e a trabalhar em equipe, direcionando a educação para a formação integral e para uma sociedade justa, democrática, inclusiva, que respeite as diferenças étnicas e culturais. Portanto, todo o trabalho deve ser feito com respeito à diversidade, permanecendo o caráter transversal; do modo como ficou, não existe obrigatoriedade considerar a diversidade.

Trabalhar com diversidade e as questões ambientais na educação amazônica implica decisão política, respeito, tolerância e empatia entre educadores e alunos, bem como espaço a atender as várias demandas que diversidade e sustentabilidade trazem. É preciso falar da história de cada povo, cultura, modos de vida, linguagens, culinária, modos de sobrevivência, sobre seus sentimentos e conflitos, oferecendo oportunidades para que os conhecimentos da realidade dos estudantes sejam trabalhados (ou para despertar a produção de novos conhecimentos), sempre va- 
lorizando a história e cultura dos povos e fazendo relação dos objetos de conhecimentos da Base Nacional Comum com os conhecimentos locais. Esse trabalho fazendo relação entre os conhecimentos universais e os conhecimentos da realidade da Amazônica é fundamental na sala de aula, e deve estar no planejamento dos professores.

O trabalho pedagógico respeitando as diversas dimensões da educação e sua relação com a diversidade cultural e social na Amazônia é tarefa árdua. Nessa direção, é necessário se opor à centralidade conferida à lógica do ensino de conteúdos tidos como universais, desconsiderando a relação que eles e as lutas epistemológicas, políticas e sociais. Nessa perspectiva, percebem-se as possibilidades de pensar uma educação adequada para os povos da região Amazônica, sem negar a importância dos saberes universais, mas garantindo o trabalho educacional com as especificidades e singularidades.

O conhecimento é universal, porém sua apropriação historicamente se restringiu a um grupo, hegemônico e excludente. Entretanto, os outros tipos de conhecimentos (saberes e conhecimentos da realidade) são construções históricas e sociais e também válidos e devem ser reconhecidos e respeitados.

A realidade deve ser entendida do ponto de vista materialista dialético, e em suas relações sociais. Assim, o real não deve ser visto, apenas como o concreto, ou seja, aquilo que está ao alcance de nossas mãos, mas tem inúmeras representações desse real. A compreensão da realidade não é algo dado. A visão imediata da realidade desse conceito real imediato é superficial, até que se pesquise exaustivamente essa realidade, para se tornar um conceito real imediato, perdido no senso comum, mas uma compreensão mais profunda do conceito de realidade vai além - é necessária uma compreensão profunda da realidade, considerando sua gênese e profundidade histórica. (KLUSKA, 2015, p. 122-123).

Nesse sentido, pensar a realidade ou realidades existentes na região Amazônica e sua conexão com a educação é pensar que a realidade é dialética: ela (a realidade) é negativa e positiva, ou seja, a realidade é algo que é dado, mas é algo que, também pode ser construído. Esse é um de- 
safio que nos remete a outra discussão: "a formação dos professores".

\section{A formação dos professores e sua relação com a educa- ção na Amazônia}

A discussão sobre formação de professores na Amazônia remete a vários questionamentos: qual é a concepção de educação que sustenta a prática desse professor? Quais os aspectos singulares da formação e da atuação dos profissionais da educação? Quais as singularidades se relacionam com a diversidade da educação na Amazônia? Quais contribuições os profissionais da educação, que atuam na Amazônia, podem oferecer no sentido de desmistificar, reconhecer e valorizar a diversidade desta região?

Pensar a formação de professores na Amazônia implica pensar como vem ocorrendo a formação inicial e continuada dos profissionais da educação a partir da promulgação da Lei no 9394/1996 - Lei de Diretrizes e Bases da Educação Nacional - LDB:

Art. 62 - A formação dos docentes para atuar na educação básica far-se-á em nível superior, em curso de licenciatura, de graduação plena, em universidades e institutos superiores de educação, admitida, como formação mínima para o exercício na Educação Infantil e nas primeiras séries do Ensino fundamental (Fundamental I), a oferecida em nível médio, na modalidade normal.

Com a consolidação da LDB, a lógica empresarial do capital entra definitivamente no cenário de disputa entre o público e o privado, na disputa pela responsabilidade na formação dos profissionais da educação, para garantir a formação mínima para iniciar na carreira do magistério.

As atuais políticas de formação inicial e continuada de professores vêm incentivando cursos de curta duração em todo o Brasil. Dentre os fatores relevantes, está a autorização dos Institutos de Educação Superior privados que fragilizou a qualidade formação de professores, especialmente dos alfabetizadores (pedagogos), ofertando formação aligeira$\mathrm{da}$, comprometem a qualidade do ensino e, consequentemente, a apren- 
dizagem.

De acordo com Evangelista e Shiroma (2015, p. 325):

As diretrizes curriculares nacionais (DCNs) para formação de professores da Educação Básica no Curso de Pedagogia, Resolução $\mathrm{CNE} / \mathrm{CP} \mathrm{n}^{\circ} 01$, de 15 de maio de 2006 (Brasil, 2006), reduziram a carga-horária das disciplinas teóricas para ampliar as das práticas e gestão. As Tecnologias de Informação e Comunicação colaboram com a instrução programada de tutores econômicos a produzir um ensino eficaz e a formação em massa de "professores de resultados".

Nos últimos anos, os cursos de professores estão mais flexíveis e rápidos, ágeis e enxutos, perdendo conteúdo e aporte teórico. A gestão do conhecimento, de sua produção e sua difusão pelas corporações e empresas de ensino, pautadas na racionalização da formação e expansão da educação à distância são resultados da expansão privada do ensino e da internacionalização do Ensino Superior.

A internacionalização das políticas educacionais, orientada pelas agências internacionais multilaterais, formulam recomendações sobre políticas públicas para países emergentes que são determinadas pelas relações econômicas.

Com o recuo da teoria, percebe-se enfraquecimento da base conceitual e teórica na formação de professores, mais conhecida como formação inicial, o que colabora com um processo de ensino e aprendizagem frágil e sem reflexão teórica - o mesmo ocorrendo com a formação continuada. Sem aprofundamento teórico das teorias educacionais e fundamentos da educação, concepção de educação, concepção de sociedade e de conhecimento, as práticas pedagógicas se traduzem numa forma ingênua, que apenas reproduz as políticas educacionais que seguem a lógica dos organismos internacionais do capital.

É preciso considerar movimentos contra-hegemônicos nas práticas educativas, como a existência de um pensamento epistemológico que chame a atenção no sentido de formar cidadãos intelectuais, armados de conhecimento, para lutar contra a ideologia dominante. Libânio (2016) sustenta as políticas públicas educacionais e a própria formação de pro- 
fessores devem contribuir para a construção de outra lógica na escola pública, que propicie a luta política pela igualdade e a inclusão social.

Para isso, tem urgência a busca de um consenso nacional entre educadores, dirigentes de órgãos públicos, políticos, pesquisadores e sindicatos, sobre a valorização da escola, do conhecimento escolar e, por consequência do trabalho dos professores. São esses os agentes centrais da qualidade do ensino e da educação. Se a educação escolar obrigatória é condição para se formar a base cultural de um povo, são necessários professores que dominem os conteúdos da cultura e da ciência e os meios de ensiná-los e que usufrutam de condições favoráveis de salário e de trabalho, bagagem cultural e científica, formação pedagógica, autoestima e segurança profissional. (LIBÂNEO, 2016, p. 60).

A problemática em jogo não envolve apenas o acesso às escolas, mas também a qualidade do ensino. São necessários salários dignos aos profissionais da educação, investimentos em infraestrutura das escolas e materiais didáticos, realização de concursos públicos, elaboração de planos de carreiras e remuneração entre outras políticas públicas de valorização profissional e do trabalho com autoestima. Ao mesmo tempo em que percebemos que o problema da educação não é mais somente o acesso, reconhecemos que a luta pela qualidade da aprendizagem é uma constante. Não podemos perder de vista que é necessário muito investimento e políticas públicas educacionais para viabilizar a qualidade da educação no Brasil.

Consequentemente, é preciso ter no horizonte a concepção de Marx (2008), segundo a qual a necessidade de mercados cada vez mais extensos impele a burguesia à formação de mão-de-obra para todo o globo, e o crescente processo de acumulação do capital requer a incorporação de mais mão-de-obra para realizar parte da fração da mais-valia responsável pela acumulação do capital.

A escola, como instrumento estatal burguês, engendra a reprodução da relação do capital, mas também pode ser resistência e luta contrahegemônica: a atuação professores engajados com a transformação da sociedade em direção a superação da sociedade de classes podem contri- 
buir, apropriando-se do conhecimento historicamente construído e ocupando os espaços da contradição para redirecionar a atividade escolar em direção oposta aos interesses do capital, em direção aos interesses das classes contra hegemônicas.

Considerando que os indivíduos são uma unidade inseparável entre seus organismos físicos, suas relações sociais e, também com o que pensam (o ambiente cognitivo), todas as condições da vida humana fundamentam-se nas produções materiais de sua produção. Neste sentido, o materialismo histórico dialético recupera um elemento importante na explicação do processo de entendimento que os idealistas procuram eliminar. Recoloca a ação, a práxis, no centro do processo de entendimento da realidade. Ou seja, é preciso considerar que o objeto, a realidade, são apreendidos na atividade humana concreta através da ação, através de um processo constante de adaptação da natureza à necessidade humana, através do trabalho, da práxis. (RODRIGUES, 2016, p. 156).

A educação popular emancipatória é o caminho para abordar a questão da produção do conhecimento em sua dimensão teórica, prática e transformadora, invertendo realidades hegemônicas e alienadas. Ela recoloca o indivíduo no centro do processo de transformação da realidade, através da ação concreta de sujeitos históricos, capazes de transformar modificar a natureza para adaptá-la às suas necessidades e lutar para mudar realidades que os oprimem.

O homem é um corpo consciente. Sua consciência, "intencionada" ao mundo, é sempre consciência de em permanente desapego até a realidade. Daí que seja próprio do homem estar em constantes relações com o mundo. Relações em que a subjetividade, que toma corpo na objetividade, constitui, com esta, uma unidade dialética, onde se gera um conhecer solitário com o agir e vice-versa. [...] É exatamente suas relações dialéticas com a realidade que iremos discutir a educação, como processo de constante libertação do homem. Educação que, por isto mesmo, não aceitará nem o homem isolado do mundo - criando este em sua consciência nem tampouco o mundo sem o homem - incapaz de transformá- 
lo. Educação que, no fundo, se tornaria a-histórica: no primeiro caso, por "faltar" o mundo, concretamente; no segundo, por carecer do homem. A história, na verdade, não existe sem os dois. Não é, de um lado, um processo mecanicista, em que os homens sejam meras coincidências dos fatos; de outro. $\mathrm{O}$ resultado de puras ideias de alguns homens, forjadas em sua consciência. Pelo contrário. Como um tempo de acontecimentos humanos, a história é feita pelos homens, ao mesmo tempo em que se vão fazendo também. E, se o que-fazer educativo, como qualquer outro querfazer dos homens, não pode dar-se a não ser "dentro" do mundo humano, que é histórico-cultural, as relações do homem-mundo devem constituir o ponto de partida de nossas reflexões sobre qualquer quer-fazer. [...] O homem é homem e o mundo histórico-cultural na medida em que ambos inacabados, se encontram numa relação permanente, na qual o homem, transformando o mundo, sofre os efeitos de sua própria transformação. (FREIRE, 1980, p. 69-87).

A educação, em Freire, ocorre nas relações do homem com o mundo num movimento dialético entre a subjetividade e a objetividade, através da práxis (ação). Esse movimento leva à libertação do homem através de processos educativos, sendo a prática educativa uma atividade mediadora na interação com o mundo na prática social. Assim, o ponto de partida e o ponto de chegada da prática educativa é sempre a prática social. Dessa maneira, a produção e a existência do homem são um processo educativo em relação como o mundo em um movimento dialético. Freire coloca a ação, a práxis, no centro do processo de entendimento da realidade, através do trabalho. Entendida dessa forma, a humanização resulta de processos educativos, onde o ser humano é produto da educação.

É importante enfatizar, contudo, a dificuldade desse caminho. As políticas públicas educacionais seguem a lógica histórica dos objetivos e estruturas do sistema capitalista, voltadas para a permanência das estruturas inconciliáveis das classes sociais e a separação da classe burguesa e proletariado, minimizando o conhecimento, especialmente da classe pobre. Essa é mais uma das estratégias do capital para garantir sua perma- 
nência sem questionamentos no auge do sistema produtivo mundial. Daí por que as propostas dirigidas a formação de professores, caminham na contramão, no que se refere às formação intelectual. (EVANGELISTA; SHIROMA, 2015).

Pensar a educação na Amazônica nesse contexto nos obriga refletir sobre a necessidade de uma formação dos professores sob outra lógica.

A formação é um processo de devir do humano, mediante o qual o indivíduo natural devém um ser cultural, uma pessoa - e bom lembrar que o sentido dessa categoria envolve complexo conjunto de dimensões que o verbo formar tenta expressar: constituir, ordenar, fundar, criar, instruir-se, colocar-se ao lado de, desenvolverse, dar-se um ser. É relevante observar que seu sentido mais rico é aquele verbo reflexivo, como que indicando que é uma ação cujo agente só pode ser o próprio sujeito. (SEVERINO, 2006, p, 621).

De acordo com o autor, a formação, enquanto experiência humana, significa a "tornar-se a ser", baseado na contínua e consciente reflexão da realidade e de sua prática docente. Severino sustenta o conceito de formação como transversal nos debates sobre educação, carregado de diferentes historicidades e processos. Nesse sentido, pensar a formação do professor é pensar numa formação enquanto aquisição de conhecimentos teóricos essenciais para subsidiar as intervenções pedagógicas referente a relação teoria e prática que permeia o trabalho do professor.

Refletir sobre a educação específica para Amazônia é refletir sobre como esse professor, cheio de conhecimentos, pode intervir na realidade. Nesse processo, além dos conhecimentos do fazer pedagógico, outros desafios se põem para os profissionais da educação que atuam na educação na Amazônia: "conhecer a realidade Amazônica" e, a partir dessa realidade, fazer conexão entre o particular e o universal, é dos mais centrais.

Só pode falar da educação na Amazônia quem vive e conhece essa realidade, quem tem o pertencimento e a defesa da diversidade ambiental, social e cultural e faz parte dessa manifestação cultural, quem 
tem o reconhecimento do seu papel social no contexto em que vive - os professores - enquanto intelectuais promotores do desenvolvimento da cultura intelectual e social. Dessa maneira, a apropriação do conhecimento através da formação inicial e continuada, a inserção na realidade, a prática social como ponto de partida e ponto de chegada são fundamentais, para os profissionais da educação que atuam na Amazônia.

Conforme Colares e Colares (2016), é longo o caminho a ser percorrido, mas já existe um indicador de que esse trabalho começou a ser pensado através de reflexões teóricas e práticas de pesquisadores que tratam do tema "Educação e realidade Amazônica" e atuam na educação da região. Nesse contexto, os educadores que se posicionam na perspectiva da educação crítica, transformadora e emancipadora, estão convidados a fazer parte desse processo. Como nos alerta Rodrigues (2018), "a escola é uma flecha", onde o conhecimento é fator decisivo de mudança de postura e consciência política para uma prática transformadora dos professores como formadores e produtores de cultura, numa perspectiva contra hegemônica.

\section{Referências}

ARROYO, Miguel; GOMES, Nilma. Possibilidades e limites para entender a relação entre o PNE e diversidade e mtempos de retrocesso: questões pendentes. In DOURADO, Luiz (org.) Plano Nacional de Educação. PNE 2014/2024. Avaliação e perspectivas. Campinas - SP: Mercado das Letras, 2017.

BRASIL. Constituição da República Federativa do Brasil. Belém: Cejup, 2005 [1989].

BRASIL, Ministério da Educação (MEC). Secretaria de Educação Básica SEB/MEC. Base Nacional Comum Curricular - BNCC. Brasília: SEB/ MEC, 2017.

COLARES, A. A; COLARES, M. L. I. S. Diversidade Cultural: Desafios Educacionais no Contexto Amazônico, 2011.

COLARES, A. A; COLARES, M. L. I. S. (orgs). Educação e realidade amazônica. Uberlândia: Navegando Publicações, 2016. 
EVANGELISTA, Olinda; SHIROMA, Eneida. Formação humana ou produção de resultados? Trabalho docente na encruzilhada. Revista Contemporânea de Educação, v. 10, p. 89-114, 2015.

FREIRE, Paulo. Educação ou comunicação? Rio de Janeiro: Paz e Terra, 1980.

GRAMSCI, Antônio. Os intelectuais e a organização da cultura. Rio de Janeiro: Civilização Brasileira, 1978.

KLUSKA, Caren Alessandra. Educação na Amazônia diante de suas singularidades. In: COLARES, Anselmo Alencar; COLARES, Maria Lília Imbiriba Sousa (org.) Educação e realidade amazônica. Uberlândia: Navegando Publicações, 2016, p. 59-72.

LIBÂNEO. José Carlos. Pedagogia e pedagogos, para quê? São Paulo: Cortez, 2010.

LIBÂNEO, José Carlos. Políticas educacionais no Brasil: desfiguramento da escola e do conhecimento escolar. Cadernos de Pesquisa (Fundação Carlos Chagas), v. 46, p. 38-62, 2016.

RODRIGUES, G. C. L. Surara Borari, Surara Araparim - a educação escolar no processo de reafirmação étnica dos Borari e Arapium da terra indígena dos Borari e Arapium da terra indígena do Maró. (Tese de doutorado). FE/Unicamp. Campinas, SP, 2016.

RODRIGUES, G. C. L. Quando a escola é uma flecha: Educação Escolar Indígena e Territorialização na Amazônia. Revista Exitus, v. 8, nº 03, p. 396-422, 2018.

SAVIANI, Dermeval. Pedagogia histórico-crítica, quadragésimo ano: novas aproximações. Campinas, SP: Autores Associados, 2019.

SAVIANI, Dermeval. Pedagogia histórico-crítica: primeiras aproximações. 11ª Ed. Campinas, SP: Autores Associados, 2013.

SEVERINO, Antônio Joaquim. A busca de sentido da formação humana: tarefa da Filosofia da Educação. Educação e Pesquisa. São Paulo, v, 32, n. 3, p. 619-634, 2006. 